\title{
Effectivity of Lactobacillus plantarum BSL against Listeria monocytogenes in rats
}

\author{
Firat Meiyasa ${ }^{1}$, Betty Sri Laksmi Jenie ${ }^{2 \star}$, Lilis Nuraida ${ }^{2,3}$, and Sutiastuti Wahyuwardani ${ }^{4}$ \\ ${ }^{1}$ Food Science Study Program, Graduate School, Bogor Agricultural University, Darmaga, Bogor 16680, Indonesia. \\ ${ }^{2}$ Department of Food Science and Technology, Bogor Agricultural University, Darmaga, Bogor 16680, Indonesia. \\ ${ }^{3}$ Southeast Asian Food and Agricultural Science and Technology (SEAFAST) Center, Bogor Agricultural University, \\ Darmaga 16680, Bogor, Indonesia. \\ 4Department of Pathology and Toxicology, Research Center for Veterinary Science, Cimanggu, Bogor 16121, Indonesia. \\ Email: sutiastutiw@yahoo.co.id.
}

Received 14 April 2017; Received in revised form 3 June 2017; Accepted 25 August 2017

\begin{abstract}
Aims: To evaluate the effectivity of Lactobacillus plantarum BSL isolated from Indonesian sauerkraut against Listeria monocytogenes ATCC 7644 through in vitro and in vivo assay.

Methodology and results: In vitro examination for antimicrobial activity against L. monocytogenes ATCC 7644 was performed using seven isolates of lactic acid bacteria (LAB). Lactobacillus plantarum BSL demonstrated the highest activity against $L$. monocytogenes and studied further in Sprague-Dawley (SD) rats. Treatment group of rats received $0.5 \mathrm{~mL}$ culture suspension $\left(10^{9} \mathrm{CFU} / \mathrm{mL}\right)$ of L. plantarum BSL and control group received $0.5 \mathrm{~mL}$ of $0.85 \% \mathrm{w} / \mathrm{v} \mathrm{NaCl}$ daily during nine days of treatment. Both groups were infected at 3rd day with $0.5 \mathrm{~mL}$ of suspension of $L$. monocytogenes $\left(10^{9} \mathrm{CFU} / \mathrm{mL}\right)$. At the $2^{\text {nd }}$ (before infection), $5^{\text {th }}, 7^{\text {th }}$, and $9^{\text {th }}$ day (after infection), the rats were sacrificed and the faeces, caecum, and caecum content were examined for the population of LAB and L. monocytogenes. Administration of $L$. plantarum BSL significantly increased the population of LAB by 1.2-1.4 log unit, while the number of $L$. monocytogenes was reduced by 1.8-1.9 log unit compared to control group eithr in the faeces, caecum, or caecum content. Administration of $L$. plantarum BSL could be able to reduce the liver and spleen damage of the experimental rats, but did not show any changes in immunoglobulin $A(\lg A)$ response in comparison with control group.

Conclusion, significance and impact of study: Lactobacillus plantarum BSL was promising as probiotic candidate with health promotion to protect the gastrointestinal from infection by L. monocytogenes ATCC 7644.
\end{abstract}

Keywords: Lactic acid Bacteria, L. plantarum BSL, L. monocytogenes, probiotic, anti listerial

\section{INTRODUCTION}

Listeria monocytogenes is a foodborne pathogen, and its infections are primarily due to the ingestion of contaminated food-products (Lomonaco et al., 2009), which may lead to serious clinical diseases (Lee et al., 2014). Lactobacillus monocytogenes may cause gastroenteritis, neural infections, and spread through the blood stream, especially in immunocompromised patients and elderly individuals. Furthermore, gestating women were highly prone to $L$. monocytogenes infections, leading to premature birth, abortion, stillbirth, and serious health problems for newborn babies (CDC, 2011; Carpentier and Clerf, 2011). Probiotics are live microorganisms which when administered in adequate amounts confer a health benefit to the host (FAO/WHO, 2002a). As one of the beneficial effects, the presence of probiotics provides protection against gastrointestinal pathogens (LourensHattingh and Viljoen, 2001). Several in vitro studies had reported that probiotics showed antagonistic activity against pathogens such as L. monocytogenes (Tulini et al., 2013; Huang et al., 2015; Leite et al., 2015).

In addition, several in vivo studies reported that probiotics from different species of Lactobacillus play an important role as antilisterial agent. L. casei significantly reduced the number of $L$. monocytogenes in the stomach, caecum, faeces, spleen and liver of the infected rats. It has also been reported that $L$. casei was able to increase cellular immunity in delayed-type hypersensitivity response (de Waard et al., 2002). Bambirra et al. (2007) further reported that Lactobacillus sakei $2 \mathrm{a}$ was able to survive in the mammal digestive tract and showed a protective effect against $L$. monocytogenes. $L$. delbrueckii UFV-H2b20 protected mice from death caused by $L$. monocytogenes infection and induced a faster clearance of bacteria in the liver, spleen and peritoneal cavity postinfection (dos Santos et al., 2011). This strain could produce high level of TNF- $\alpha$ in serum, peritoneal cavity and gut and increase the production of nitric oxide in serum and induced higher production of $\mathrm{IL}-10$ in the 
mucosal immune system. High level of TNF- $\alpha$ and IL-10 will improve the immune system

Indigenous lactic acid bacteria (LAB) had been widely isolated from various Indonesian fermented foods among others were fermented vegetables, fruits, legumes, fish and fresh beef. One promising LAB strain ( $L$. plantarum $B S L$ ), isolated from sauerkraut was considered as a good probiotic candidate due to its ability to survive the gastric environment $(5 \%$ bile salt and $\mathrm{pH} 2.5)$ and showed significant health benefit. L. plantarum BSL demonstrated inhibitory activity against pathogens such as $B$. cereus, $S$. aureus, and E. coli (Kusumawati et al., 2003) and in vivo experiment revealed that the LAB was able to reduce total cholesterol of rat blood serum, enhance lactobacilli growth, and suppress coliform and staphylococci in rat faeces (Kusumawati et al., 2008). However, it is not known whether this strain presents an in vivo effect against L. monocytogenes ATCC 7644. In this present study, L. plantarum BSL was evaluated for antilisterial activity in rats using L. monocytogenes ATCC 7644 as indicator bacteria.

\section{MATERIALS AND METHODS}

\section{Rats and diets}

Sprague-Dawley rats (Rattus norvegicus) were obtained from Faculty of Animal Science, Bogor Agricultural University. A total of 60 rats (5-6 weeks of age) were randomly allocated and housed in cages (one rat per cage). The rats were housed under standard conditions in the barrier unit: light/dark schedule was constant at 12/12 $\mathrm{h}$ and humidity at 50-60\% (de Waard et al., 2002). All experiments were approved by Animal Ethical Committee of Bogor Agricultural University. Diet of $20 \mathrm{~g} / \mathrm{rat} /$ day of feed was formulated according to AOAC (2005) consisted of casein, corn oil, mineral mix, vitamin mix, carboxymethyl cellulose (CMC), water, and corn starch.

\section{Bacterial culture}

Seven LAB isolates (L. plantarum BSL, L. plantarum kik, $L$. rhamnosus R23, L. plantarum pi28a, L. plantarum ip, $L$. plantarum tpyk, L. plantarum MB427) were obtained from Laboratory of Food Microbiology, Department of Food Science and Technology, Bogor Agricultural University. These LAB strains were grown in MRS broth (Oxoid $\mathrm{CM} 359$ ) at $37^{\circ} \mathrm{C}$ for $24 \mathrm{~h}$, followed by pour plating in MRS agar (Oxoid CM361) incubated at $37^{\circ} \mathrm{C}$ for $24-48 \mathrm{~h}$ for counting the bacterial cells. Lactobacillus monocytogenes strain ATCC 7644 was cultured in BHI broth (Oxoid $\mathrm{CM} 1136$ ) incubated at $37^{\circ} \mathrm{C}$ for $24 \mathrm{~h}$, and then counted in Listeria Selective Agar Base (Oxoid CM856), after incubation at $37^{\circ} \mathrm{C}$ for $24-48 \mathrm{~h}$.

To prepare cell suspension, a $24 \mathrm{~h}$ LAB culture in MRSB was centrifuged $\left(2000 \mathrm{~g}, 10 \mathrm{~min}, 4^{\circ} \mathrm{C}\right)$ and the cell pellet was resuspended in $10 \mathrm{~mL}$ volume of $0.85 \% \mathrm{NaCl}$. The number of LAB cells in suspension was enumerated in MRS agar. Similar method was applied for $L$. monocytogenes ATCC 7644 , only the media used was $\mathrm{BHI}$ broth.

\section{Determination of antimicrobial activity of Lactobacillus sp against $L$. monocytogenes ATCC 7644 by in vitro assay (Nuraida et al., 2012)}

Antibacterial activity of seven Lactobacillus sp isolates mentioned above were determined against $L$. monocytogenes ATCC 7644 using direct contact method. The culture of all Lactobacillus sp. and L. monocytogenes ATCC 7644 were refreshed in MRSB and BHI media respectively, and incubated for $24 \mathrm{~h}$ at $37^{\circ} \mathrm{C}$ and $35^{\circ} \mathrm{C}$, respectively. One $\mathrm{mL}$ suspension of Lactobacillus $\mathrm{sp}\left(10^{8}\right.$ $\mathrm{CFU} / \mathrm{mL}$ ) and $L$. monocytogenes $\left(10^{5} \mathrm{CFU} / \mathrm{mL}\right)$ from appropriate dilution were further inoculated into tube containing $8 \mathrm{~mL}$ of skim milk and incubated at $35^{\circ} \mathrm{C}$ for 24 $h$. The population of $L$. monocytogenes before and after incubation were counted on Listeria Selective Media Agar. Lactobacillus isolate that showed the highest antimicrobial activity was selected for in vivo experiment.

\section{In vivo experiment of antilisterial activity (de Waard et al., 2002)}

Rats having initial weight of $100-140 \mathrm{~g}$ were acclimatized for 7 days and received a standard diet. In anti-listerial experiment, a total of 48 rats were divided into 2 groups (24 rats for treatment group and 24 rats for control group).

LAB strain which showed high activity against $L$. monocytogenes ATCC 7644 obtained from in vitro assay was used in this in vivo assay. The selected LAB strain and L. monocytogenes ATCC 7644 were grown in MRS broth and BHI broth respectively for $24 \mathrm{~h}$ at $37^{\circ} \mathrm{C}$. These cultures were centrifuged (2000 $\left.\mathrm{g}, 10 \mathrm{~min}, 4^{\circ} \mathrm{C}\right)$ and resuspended in $0.85 \% \mathrm{NaCl}$ in order to obtain cell number up to $10^{9} \mathrm{CFU} / \mathrm{mL}$. This suspension was then administered to rats by the oral route.

The treatment group was administered with $L$. plantarum BSL culture $\left(10^{9} \mathrm{CFU} / \mathrm{mL}\right)$, while the control group was administered with $0.85 \% \mathrm{NaCl}(0.5 \mathrm{~mL} / \mathrm{rat} / \mathrm{day})$ for 9 days (day-0 - day-9, except at day-3). Rats were then infected by $0.5 \mathrm{~mL}$ of $L$. monocytogenes ATCC 7644 culture $\left(10^{9} \mathrm{CFU} / \mathrm{mL} / \mathrm{rat}\right)$ at day-3 for both treatment and control groups.

Rats were weighed every two days while feed consumption or feed efficiency was calculated daily. Rats were sacrificed by cervical dislocation in day-2 (before infected by $L$. monocytogenes), day- 5 , day- 7 , and day- 9 (after infected by L. monocytogenes) to obtain samples for enumeration of $L A B$ and $L$. monocytogenes population in faeces, caecum, and caecum content of rats. Analysis of $\lg \mathrm{A}$ was carried out in serum samples taken from rat's heart before sacrificed using turbidimetric immunoassay method of Apo B Kit (KBC, 2009). For histopathology analysis, rat spleen and liver were stained using Hematoxylin-Eosin (HE) and observed the cell damage under light microscope (Kiernan, 1999). Data were evaluated using analysis of variance (ANOVA), and the 
significance of the differences was verified using Duncan test in SAS software (version 16).

\section{RESULTS AND DISCUSSION}

\section{In vitro assay on antimicrobial activity of $L A B$ against L. monocytogenes ATCC 7644}

In general, all of the $L A B$ strains tested showed antimicrobial activities against $L$. monocytogenes ATCC 7644 with different degree of inhibition at the range of reduction between 0.7-3.0 log CFU/mL. Two strains ( $L$. plantarum tpyk and $L$. plantarum BSL) exhibited highest inhibitory effect ( $3 \log C F U / \mathrm{mL}$ ) among other LAB strains (Figure 1). Wilson et al. (2005) found that L. plantarum SK1 displayed antimicrobial activity against $L$. monocytogenes UMCC98 by a reduction of more than 3 $\log C F U / m L$. Aquilar et al. (2011) also reported that $L$. plantarum LB279 effectively inhibited the growth of $L$. monocytogenes CECT 4032 by 5 log unit compared to other pathogens.

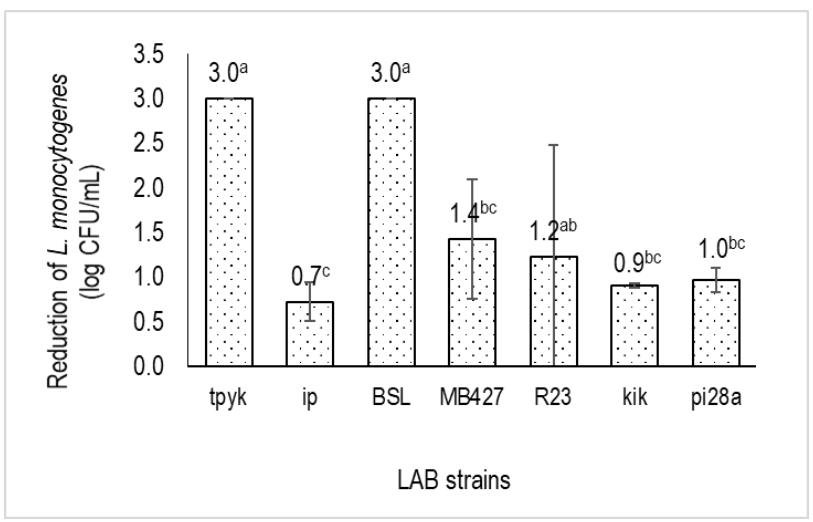

Figure 1: Antimicrobial activities of L. plantarum strains (tpyk, ip, BSL, MB427, kik, pi28a) and L. rhamnosus R23 against $L$. monocytogenes ATCC 7644. (All data were an average of two replicates, different letter superscripts following the values mean significantly different $(p<0.05))$.

Other species of Lactobacillus also exhibited antimicrobial activities. L. salivarius CECT5713 displayed antimicrobial activity against Salmonella choleraesuis CECT4155 (Olivares et al., 2006). Lactobacillus rhamnosus $\mathrm{R} 14$, L. rhamnosus $\mathrm{R} 23$ and $L$. rhamnosus B16 demonstrated strong antimicrobial properties against E. coli K1.1 (Nuraida et al. 2012). In addition, Lactococcus piscium CNCM I-4031 was able to reduce the population of $L$. monocytogenes by 3-4 log during $24 \mathrm{~h}$ (Saraou et al., 2016). In general, probiotics promoted desirable effects on health, but the positive effects of probiotics were usually attributed to strain specific (Williams, 2010). Based on the result of in vitro analysis, L. plantarum BSL was selected to be evaluated further for antilisterial activity in rats challenged with $L$. monocytogenes ATCC 7644.

\section{Body weight gain and feed consumption of rats}

Significant changes were observed during the experiment including weight gain and feed consumption of rats (Table 1). Both control and experiment group showed weight gain at day 2 , but significantly higher value $(p<0.05)$ was observed in experiment group than control group. The results showed that administration of $L$. plantarum BSL for 2 days in the treatment group was able to increase the weight gain of rats. Further administration of $L$. plantarum BSL did not affect the weight gain of rats, no further additional weight gain of rats was observed until 9 dayexperiment either in control or treatment group.

The average feed consumption of 9-day-treatment in the treatment group was significantly higher (12.1 $\mathrm{g} / \mathrm{rat} /$ day) than the control group (10.8 $\mathrm{g} / \mathrm{rat} /$ day) (Table 1). This indicated that the administration of $L$. plantarum BSL could improve feed consumption of rats infected by $L$. monocytogenes. Similar result was found by Oyetayo (2004) that $L$. acidophilus was able to increase feed consumption and body weight gain of rats infected by enterotoxigenic E. coli (ETEC). Gross et al. (2008) also reported that $L$. plantarum $299 \mathrm{v}$ was able to increase feed consumption and body weight gain in diarrhea rats. In addition, L. plantarum $2 \mathrm{C} 12$ and $L$. acidophilus 2B4 isolated from Indonesian meat were also able to improve feed consumption and body weight gain of rats infected by enteropathogenic E. coli (EPEC) (Arief et al., 2010).

The presence of probiotic including $L$. plantarum BSL possibly increase the absorption of nutrients by producing some digestive enzymes, such as proteolytic enzymes. In addition, probiotic also is able to release of free amino acid and synthesis of vitamins that are needed for the growth of host (Parvez et al., 2006).

Table 1: The effects of orally administered L. plantarum BSL on feed consumption and body weight gain of rats during nine-day experiment. Different superscripts following the values in the same column and row mean significantly different $(p<0.05)$.

\begin{tabular}{|c|c|c|c|c|c|}
\hline \multirow{4}{*}{ group } & \multicolumn{4}{|c|}{ Rats weight gain (g/rat) } & \multirow{4}{*}{$\begin{array}{l}\text { Feed consumption } \\
(\mathrm{g} / \mathrm{rat} / \text { day })\end{array}$} \\
\hline & \multicolumn{4}{|c|}{ Day- } & \\
\hline & 2 & 5 & 7 & 9 & \\
\hline & (Before infected) & & (After infected) & & \\
\hline Control & $3.83^{\mathrm{b}} \pm 0.23$ & $4.17^{\mathrm{b}} \pm 0.49$ & $4.17^{b} \pm 0.23$ & $5.50^{\mathrm{b}} \pm 1.17$ & $10.78^{b} \pm 2.15$ \\
\hline Treatment & $10.35^{\mathrm{a}} \pm 2.35$ & $9.84^{a} \pm 1.64$ & $7.00^{\mathrm{a}} \pm 1.41$ & $7.33^{\mathrm{a}} \pm 1.41$ & $12.06^{\mathrm{a}} \pm 1.27$ \\
\hline
\end{tabular}


Table 2: The effects of orally administered L. plantarum BSL on total LAB population in the faeces, caecum, and caecum content of rats, either on both control and treatment group during nine-day experiment. Different superscripts following the values in the same column and row mean significantly different $(p<0.05)$.

\begin{tabular}{lcccc}
\hline \multirow{2}{*}{ Group } & \multicolumn{4}{c}{ Day of treatment } \\
\cline { 2 - 5 } & $\begin{array}{c}2 \\
\text { (Before infected) }\end{array}$ & 5 & $\begin{array}{c}7 \\
\text { (After infected) }\end{array}$ & 9 \\
\hline Faeces (log CFU/g) & & & \\
Control & $8.0 \pm 0.02^{\mathrm{b}}$ & $7.9 \pm 0.37^{\mathrm{b}}$ & $7.7 \pm 0.61^{\mathrm{b}}$ & $8.0 \pm 0.39^{\mathrm{b}}$ \\
Treatment & $9.1 \pm 0.00^{\mathrm{a}}$ & $9.4 \pm 0.00^{\mathrm{a}}$ & $9.3 \pm 0.18^{\mathrm{a}}$ & $9.4 \pm 0.01^{\mathrm{a}}$ \\
\hline Caecum (log CFU/cm $)$ & & & & \\
Control & $7.7 \pm 0.30^{\mathrm{c}}$ & $7.7 \pm 0.35^{\mathrm{c}}$ & $7.8 \pm 0.26^{\mathrm{bc}}$ & $7.8 \pm 0.61^{\mathrm{abc}}$ \\
Treatment & $8.9 \pm 0.45^{\mathrm{a}}$ & $8.9 \pm 0.59^{\mathrm{ab}}$ & $9.0 \pm 0.51^{\mathrm{a}}$ & $8.7 \pm 0.45^{\mathrm{abc}}$ \\
\hline Caecum content (log CFU/g) & & & & \\
Control & $7.8 \pm 0.27^{\mathrm{b}}$ & $7.5 \pm 0.18^{\mathrm{b}}$ & $7.8 \pm 0.30^{\mathrm{b}}$ & $8.1 \pm 0.37^{\mathrm{b}}$ \\
Treatment & $9.1 \pm 0.16^{\mathrm{a}}$ & $9.0 \pm 0.49^{\mathrm{a}}$ & $9.4 \pm 0.03^{\mathrm{a}}$ & $9.2 \pm 0.27^{\mathrm{a}}$ \\
\hline
\end{tabular}

\section{Total LAB in caecum}

$\mathrm{LAB}$ integrity in the gut was a fundamental factor for probiotics (FAO/WHO, 2002b). The number of $L A B$ in caecal mucosa demonstrated that $L A B$ attached on the mucosa of caecum (Table 2). In rats, administration of $L$. plantarum BSL could affect total $L A B$ in the caecal mucosa. At day-2, administration of $L$. plantarum BSL increased total LAB in the caecal mucosa compared to control. The results revealed that in day- 2 (before infected by $L$. monocytogenes). total $L A B$ in the caecal mucosa of the treatment group was $8.9 \log \mathrm{CFU} / \mathrm{cm}^{2}$ which was approximately $1.2 \mathrm{log} \mathrm{CFU} / \mathrm{cm}^{2}$ higher than the control group $\left(7.7 \log \mathrm{CFU} / \mathrm{cm}^{2}\right)$. In day-5, day-7, and day-9 (after infected by L. monocytogenes), the number of LAB were not significantly different in both control (7.7-7.8 log $\mathrm{CFU} / \mathrm{cm}^{2}$ ) and treatment group (8.7-9.0 log CFU/ $/ \mathrm{cm}^{2}$ ).

Table 2 presented higher total $L A B$ in the caecal mucosa of treatment rats than control, indicating that $L$. plantarum BSL was able to get through barriers in digestive tract including low $\mathrm{pH}$ (in the stomach), bile salt (in the gut), and ultimately reached caecal mucosa in the small intestine. Kusumawati et al. (2003) reported that $L$. plantarum BSL was resistant to $5 \%$ bile salt and $\mathrm{pH} 2.5$, suggesting that $L$. plantarum BSL had high survival and ability to adhere to the epithelial cell surface. Gross et al. (2008) found that Lactobacillus spp. population in the small intestine of rats treated with $L$. plantarum $299 \mathrm{v}$ was higher $\left(10^{6} \mathrm{CFU} / \mathrm{g}\right)$ than control $\left(10^{5} \mathrm{CFU} / \mathrm{g}\right)$. Emmawati et al. (2016) stated that L. plantarum MB427 had adhesion and competition ability with L. monocytogenes, EPEC and $S$. Typhimurium, thus enabling the $\mathrm{LAB}$ to attach on the intestinal mucosa.

\section{Total LAB in caecum content}

Microflora composition in the caecum content may represent microorganism contain in the faeces. Rats caecum was a site in which some food nutrients were fermented by gut microflora as observed in human colon (Liong and Shah, 2006).

In the treatment group, administration of $L$. plantarum BSL significantly increased $(p<0.05)$ total LAB in caecum content compared to control group (Table 2). At day-2 (before infected by $L$. monocytogenes), total LAB in the caecum content $(9.1 \mathrm{log} C F U / g)$ was higher than the control group (7.8 log CFU/g). At day-5, day-7, day-9 (after infected by L. monocytogenes), the number of LAB were not significantly different in both control $(7.5-8.1 \mathrm{log}$ CFU/g) and treatment group (9.0-9.4 log CFU/g).

Total LAB in the caecum content of the control group was lower than the treatment group. Similar findings were also found related to faeces and caecum of rats. $L$. plantarum BSL was able to increase total $\mathrm{LAB}$ in the caecum content by $1.4 \mathrm{log} C F U / g$. This result was in accordance with Arief et al. (2010) that probiotic treatment could raise $L A B$ in the caecum content by $1.0 \mathrm{log} C F U / g$ in comparison with control.

Lactobacillus plantarum BSL was prominently improved total $L A B$ in the caecum content of rats treated with L. monocytogenes. L. plantarum BSL showed proper growth in digestive tracts, leading to higher total $L A B$ in the caecum content. Emmawati et al. (2015) also reported that rats with the treatment of $L$. plantarum MB427 could get through the gastrointestinal tract of rats and retain their population in comparison with control.

\section{Effects of $L$. plantarum BSL administration on the population of $L$. monocytogenes in faeces, caecum, and caecum content}

\section{Numbers of L. monocytogenes in faeces}

Administration of $L$. plantarum BSL on rats enhanced the number of LAB population in faeces of rats, which was negatively correlated with $L$. monocytogenes population in faeces. At day-2 (before infected by L. monocytogenes), $L$. monocytogenes was found in the faeces (3-4 log CFU/g) in both control and treatment group (Table 3). The presence of $L$. monocytogenes in the faeces before rats infected by $L$. monocytogenes may be obtained from feed consumption and rice husk during adaptation for seven days.

At day $-5,-7$ and -9 , after infected by $L$. monocytogenes the number of $L$. monocytogenes in the faeces in the treatment group (5.1-5.5 log CFU/g) was lower than the control group (7.1-7.2 log CFU/g). This results suggested that $L$. plantarum $B S L$ had antilisterial 
Table 3: The effects of orally administered L. plantarum BSL on number of $L$. monocytogenes in the faeces, caecum, and caecum content of rats, either on both control and treatment group during nine-day experiment. Different superscripts following the values in the same column and row mean significantly different $(p<0.05)$.

\begin{tabular}{lllll}
\hline \multirow{2}{*}{ Group } & Day of treatment & & \\
\cline { 2 - 5 } & $\begin{array}{l}2 \\
\text { (Before infected) }\end{array}$ & $\begin{array}{l}5 \\
\text { (After infected) }\end{array}$ & 7 & 9 \\
\hline $\begin{array}{l}\text { Faeces }(\log C F U / g) \\
\text { Control }\end{array}$ & $3.89 \pm 0.04^{\mathrm{d}}$ & $7.19 \pm 0.10^{\mathrm{a}}$ & $7.09 \pm 0.04^{\mathrm{a}}$ & $7.17 \pm 0.11^{\mathrm{a}}$ \\
Treatment & $3.74 \pm 0.25^{\mathrm{d}}$ & $5.53 \pm 0.04^{\mathrm{b}}$ & $5.34 \pm 0.06^{\mathrm{bc}}$ & $5.11 \pm 0.13^{\mathrm{c}}$ \\
\hline Caecum $\left(\log C F U / \mathrm{cm}^{2}\right)$ & $3.91 \pm 0.01^{\mathrm{c}}$ & $7.07 \pm 0.16^{\mathrm{a}}$ & $6.80 \pm 0.48^{\mathrm{a}}$ & $6.89 \pm 0.55^{\mathrm{a}}$ \\
Control & $3.42 \pm 0.64^{\mathrm{c}}$ & $5.23 \pm 0.03^{\mathrm{b}}$ & $5.15 \pm 0.22^{\mathrm{b}}$ & $5.09 \pm 0.15^{\mathrm{b}}$ \\
\hline Treatment & & & & \\
\hline Caecum content $(\log C F U / g)$ & $3.27 \pm 0.01^{\mathrm{c}}$ & $7.19 \pm 0.04^{\mathrm{a}}$ & $7.17 \pm 0.01^{\mathrm{a}}$ & $7.14 \pm 0.06^{\mathrm{a}}$ \\
Control & $3.07 \pm 0.12^{\mathrm{c}}$ & $5.53 \pm 0.08^{\mathrm{b}}$ & $5.47 \pm 0.47^{\mathrm{b}}$ & $5.32 \pm 0.25^{\mathrm{b}}$ \\
\hline
\end{tabular}

activity in rats faeces upto $1.9 \mathrm{log} \mathrm{CFU} / \mathrm{g}$ reduction compared to control.

The present result was in accordance with the result reported by de Waard et al. (2002) that administration of L. casei Shirota strain YIT9029 could improve resistance against $L$. monocytogenes strain L242/73 in rats. The occurrence of $L$. casei Shirota led to the reduction of $L$. monocytogenes in rat's faeces. However, contrast to the result reported by Bambirra et al. (2007) it was found that administration of $L$. sakei 2 a did not affect the population of $L$. monocytogenes Scott $A$ in mice faeces $(L$. monocytogenes population in both control and treatment group were similar to $10^{9} \mathrm{CFU} / \mathrm{g}$ ). This result suggested that reduction of $L$. monocytogenes depended on the species of LAB, as described by Williams (2010) that positive effects of probiotics were attributed to strain specific.

Numbers of L. monocytogenes in caecum and caecum content

Administration of $L$. plantarum BSL significantly $(p<0.05)$ reduced $L$. monocytogenes population in caecum and caecum content of treatment group compared to control group (Table 3 ). Similar to faeces, L. monocytogenes reduction was also observed in caecum and caecum content. At day-2 the population of $L$. monocytogenes was 3-4 log CFU/g in both control and treatment group.

At day-5, day-7, and day-9, lower population of $L$. monocytogenes was observed in caecum (5.1-5.2 log $\mathrm{CFU} / \mathrm{cm}^{2}$ ) and caecum content (5.3-5.5 log CFU/g) of treatment group than caecum $\left(6.8-7.1 \mathrm{log} \mathrm{CFU} / \mathrm{cm}^{2}\right)$ and caecum content (7.1-7.2 log CFU/g) of control group. The number of $L$. monocytogenes at day- $5,-7$ and -9 were relatively stable either in control or treatment group, assuming that there was no further growth of $L$. monocytogenes.

This result showed that $L$. plantarum BSL administration to rats significantly reduced the $L$. monocytogenes population in caecum and caecum content upto 1.8 log unit. LAB naturally occur in the digestive tract of the rat. Total $L A B$ in caecum and caecum content of control and treatment group was about $7 \mathrm{log}$ CFU/g and 9 log CFU/g respectively. The presence of $L A B$ in caecum and caecum content significantly affected $L$. monocytogenes population. The results confirmed that $L$. plantarum BSL demonstrated antagonistic effects on $L$. monocytogenes in rats eventhough with lower activity than in vitro study. In vitro experiment showed higher reduction (3 log CFU/mL) of $L$. monocytogenes population by $L$. plantarum BSL Lower reduction of $L$. monocytogenes in rats might be due to challenging factors existed in gut environment related to the co-aggregation, competition and exclusion ability of $L$. plantarum BSL with the pathogen.

Lactobacillus monocytogenes could be inhibited by probiotics through the production of antimicrobial substances such as organic acids, diacetyl, hydrogen peroxide, and bacteriocin. Reduction of $\mathrm{pH}$ as a result of organic acids (primarily lactic acid and acetic acid) produced in gut promoted bactericidal or bacteriostatic activity (Shah, 2007). de Waard et al. (2002) found that inclusion of $L$. casei Shirota strain YIT9029 could attenuate $L$. monocytogenes in rats caecum. Arief et al. (2010) reported that $L$. acidophilus 2B4 was effective in retarding $E$. coli growth in caecal mucosa and caecum content in comparison with control. In addition, $L$. plantarum MB427 was reported being able to compete and displace EPEC, thus decreasing $E$. coli population in caecum and caecum content of rat (Emmawati et al., 2015).

\section{Effects of L. plantarum BSL on IgA response of rat serum}

The immune response was evaluated using $\lg \mathrm{A}$ antibody test. Administration of $L$. plantarum BSL showed that $\operatorname{IgA}$ of control (12.0-12.5 mg/dl) and treatment (11.5-13.5 $\mathrm{mg} / \mathrm{dl}$ ) group were not significantly different in both groups in day-2 (before infected by L. monocytogenes) and in day-5, day-7, day-9 (after infected by L. monocytogenes) (Figure 2). Administration of L. plantarum BSL after 9 days did not significantly affect the IgA responses. According to Ward (2012) L. monocytogenes ATCC 7644 strain used in the present study was known included in serotype 1/2c that recognized to have lower risk than another serotype (Jaradat and Bhunia, 2003). This may explain that this strain did not affect the $\lg A$ response. 
Ren et al. (2015) reported that Lactobacilli strains showed the capacity to induce $\lg A$ production differently but after 20 days of administration the level of IgA was relatively stable and showed no significant difference between control and treatment groups. However, Galdeano and Perdigón (2006) reported that IgA response increased after 7 days of $L$. casei CRL 431 administration compared to control. Several studies have demonstrated that ability of probiotics to enhance immune responses were strain specific (Amalaradjou and Bhunia, 2012).

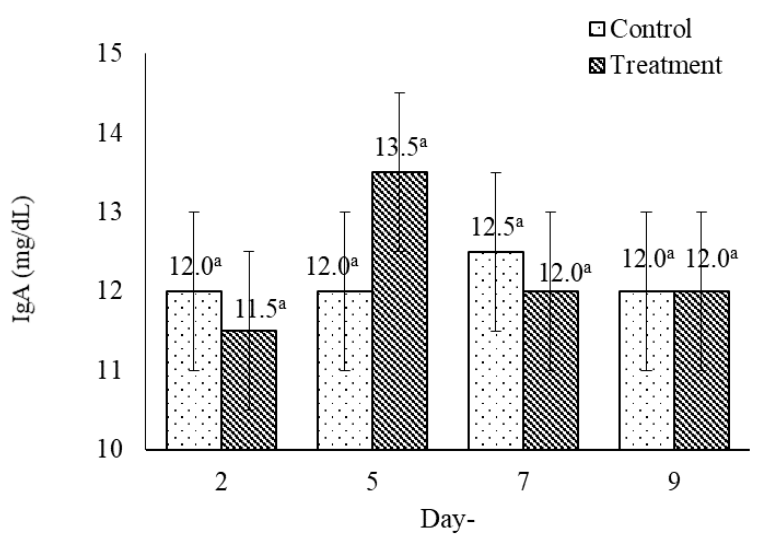

Figure 2: The effects of orally administered $L$. plantarum BSL on IgA response of rats during nine-day experiment. [All data were an average of two replicates, different letter superscripts following the values mean significantly different $(p<0.05)]$.

\section{Effects of L. plantarum BSL on damage of rat liver and spleen}

The histopathology analysis was performed to observe the ability of $L$. plantarum BSL in retarding the damage of liver and spleen. The results revealed that administration of $L$. plantarum BSL showed by the descriptive analysis could reduce tissue damage of liver (Table 4) and spleen tissues (Table 5) compared to control. As shown in Table 4 , before infected with $L$. monocytogenes (day-2), rat's liver tissues were free of vacuolization of hepatocytes cell but other forms of damages inlcuding edema, necrosis, infiltration of lymphoid cells, and proliferation of bile tract were observed, either in control or treatment group, with various levels of damages. Administration of $L$. plantarum BSL for 9 days after rats infected with $L$. monocytogenes showed evidence in reducing the damages observed mainly for edema, necrosis and infiltration of lymphoid cells of liver tissues. On the other hand, the damages of infected rats in control group were still observed and even more severe at day 9 with necrosis level increased to heavy level $(+++)$ in $50 \%$ of the rats population $(3 / 6)$. In contrast, treatment group at day- 9 showed no necrosis in four rats (4/6) and minor necrosis in other rats (2/6). Edema, vacuolization of hepatocyte cells and proliferation of bile tract of infected rats $(5 / 6)$ in control group were still observed until day-9-experiment and one rat (1/6) showed heavy $(+++)$ level of bile tract proliferation. In the experiment group, negative vacuolization was detected in all rats (6/6), and minor level of edema and proliferation were detected in $50 \%$ population $(3 / 6)$, while the rest of population $(3 / 6)$ were negative.

Spleen damage in rats was observed inluding depletion of lymphoid cells, extension of pulp area and cell proliferation as shown in Table 5 . Similar to liver damage, damages of rats spleen such as depletion of lymphoid cells and extension of pulp area but no cell proliferation were detected at day 2 , before infected with $L$. monocytogenes either in control or experiment group. Administration of $L$. plantarum BSL for nine days could be able to reduce the spleen damage, as observed in treated rats, while in control rats, all forms of spleen damage were still observed at day 9 . In the treated rats, 4 rats (4/6) were free of lymphoid depletion, and 2 rats $(2 / 6)$ suffered only minor depletion, and no extension of pulp area were detected in most of the treated rats $(5 / 6)$ and neither of cell proliferation occurred in all rats $(6 / 6)$. As in control rats, most of them (5/6) were suffer of lymphoid depletion and extension of pulp area, but only two rats $(2 / 6)$ showed minor proliferation. These results provided evidents that administration of $L$. plantarum BSL were advantage in reducing tissue damage of liver and spleen of rats. This indicates that the administration of $L$. plantarum BSL during nine-days was able to reduce the damage of liver and spleen tissue compared to control.

As previously reported by de Waard et al. (2002) that administration of $L$. casei Shirota strain YIT9029 on rats infected by $L$. monocytogenes L242/73 showed no significant difference between control and experimental groups as histopathological lesions due to $L$. monocytogenes infection were not obvious in the spleen and the same number of necrotic foci in liver after infected during 2-day. Martins et al. (2009) also reported that administration of probiotic bacteria did not cause an alteration in the morphology of intestines, liver, and spleen. In addition, the number of küpffer did not significantly different between control and experimental groups.

However, the results reported by Bambirra et al. (2007) showed the opposite way with those of the previous study, that the administration of $L$. sakei 2 a could be able to reduce tissues damage of liver and spleen rats infected by $L$. monocytogenes Scott A compared to control. Shown by lesions were more severe in the control group and characterized by a destruction of the mucosa with infiltrate of inflammatory cells, predominantly macrophages and neutrophils. Moreover, dos Santos et al. (2011) also reported that administration of $L$. delbrueckii UFV-H2b20 significantly reduced the damage of liver caused by infection of L. monocytogenes $10403 S$.

Administration of $L$. delbrueckii UFV-H2b20 was significantly reduced the size of the inflammatory infiltrate, relative area of inflammatory lesions was smaller, tissue damage such as necrosis and degenerative changes of hepatocytes lower than the control (dos Santos et al., 2011). 
Malays. J. Microbiol. Vol 14(3) 2018, pp. 281-292

Table 4: Reduction of liver damage during nine-day administration of L. plantarum BSL.

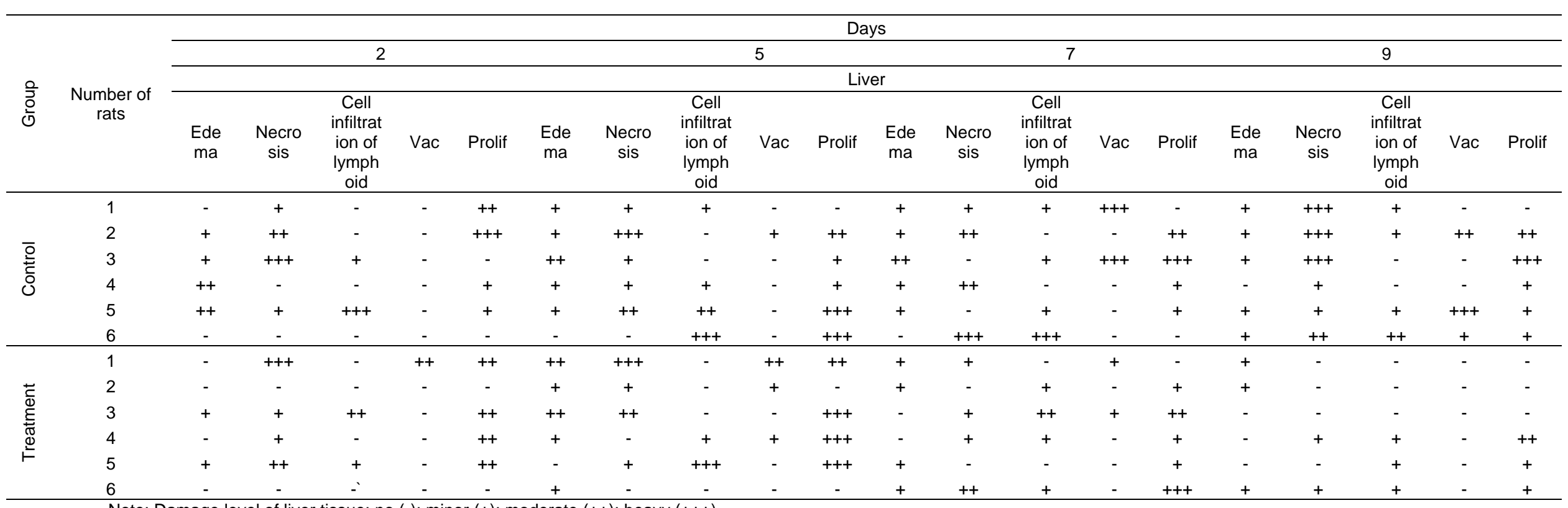

Damage level of liver tissue: no (-); minor (+); moderate (++); heavy (+++) 
Malays. J. Microbiol. Vol 14(3) 2018, pp. 281-292

Table 5: Reduction of spleen damage during nine-day administration of $L$. plantarum BSL.

\begin{tabular}{|c|c|c|c|c|c|c|c|c|c|c|c|c|c|}
\hline \multirow{4}{*}{$\begin{array}{l}\text { 음 } \\
\stackrel{0}{0}\end{array}$} & \multirow{4}{*}{$\begin{array}{l}\text { Number } \\
\text { of rats }\end{array}$} & \multicolumn{12}{|c|}{ Days } \\
\hline & & \multicolumn{3}{|c|}{2} & \multicolumn{2}{|r|}{5} & \multicolumn{4}{|c|}{7} & \multicolumn{3}{|c|}{9} \\
\hline & & \multicolumn{12}{|c|}{ Spleen } \\
\hline & & $\begin{array}{c}\text { Depletion } \\
\text { of } \\
\text { lymphoid } \\
\text { cells }\end{array}$ & $\begin{array}{c}\text { Extension } \\
\text { of pulp } \\
\text { area }\end{array}$ & $\begin{array}{c}\text { Cell } \\
\text { proliferati } \\
\text { on }\end{array}$ & $\begin{array}{l}\text { Depletion } \\
\text { of } \\
\text { lymphoid } \\
\text { cells }\end{array}$ & $\begin{array}{l}\text { Extension } \\
\text { of pulp } \\
\text { area }\end{array}$ & $\begin{array}{l}\text { Cell } \\
\text { prolifer } \\
\text { ation }\end{array}$ & $\begin{array}{c}\text { Depletion } \\
\text { of } \\
\text { lymphoid } \\
\text { cells }\end{array}$ & $\begin{array}{c}\text { Extension } \\
\text { of pulp } \\
\text { area }\end{array}$ & $\begin{array}{c}\text { Cell } \\
\text { proliferati } \\
\text { on }\end{array}$ & $\begin{array}{l}\text { Depletion } \\
\text { of } \\
\text { lymphoid } \\
\text { cells } \\
\end{array}$ & $\begin{array}{l}\text { Extension } \\
\text { of pulp } \\
\text { area }\end{array}$ & $\begin{array}{c}\text { Cell } \\
\text { proliferat } \\
\text { ion }\end{array}$ \\
\hline \multirow{6}{*}{$\begin{array}{l}\overline{0} \\
\text { 늠 } \\
0\end{array}$} & 1 & + & + & - & + & - & - & - & + & - & + & + & - \\
\hline & 2 & - & + & - & + & + & + & + & ++ & + & ++ & - & + \\
\hline & 3 & + & - & - & + & + & - & + & - & - & + & + & - \\
\hline & 4 & + & + & - & + & + & - & + & ++ & - & - & + & - \\
\hline & 5 & + & - & - & + & + & + & ++ & - & + & + & + & + \\
\hline & 6 & ++ & - & - & - & + & + & + & +++ & + & ++ & - & - \\
\hline \multirow{6}{*}{ 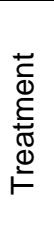 } & 1 & + & - & - & ++ & + & - & + & + & - & - & + & - \\
\hline & 2 & + & + & - & + & + & - & + & - & - & - & - & - \\
\hline & 3 & - & - & - & + & + & - & + & + & - & - & - & - \\
\hline & 4 & + & - & - & - & - & - & + & + & - & - & - & - \\
\hline & 5 & + & - & - & + & + & + & - & - & - & + & - & - \\
\hline & 6 & - & - & - & - & - & + & - & ++ & - & + & - & - \\
\hline
\end{tabular}

Note: Damage level of spleen tissue: no (-); minor (+); moderate (++); heavy (+++) 
These results suggested that not all of Lactobacillus $\mathrm{sp}$ can reduce the tissues damage on liver and spleen due to $L$. monocytogenes infection. Some of Lactobacillus species have been reported to reduce tissues damage such as liver and spleen. Possibly through the production of antagonistic compounds, inhibited L. monocytogenes adhesion to tissues, competition for nutrients, and modulating functions of the immune system (improves resistance to an infection of pathogens, increase the macrophages activity and antibody or cytokine production) (Bambirra et al., 2007).

\section{CONCLUSIONS}

Lactobacillus plantarum BSL was shown by in vitro assay had the highest antimicrobial activity among seven indigenous $\mathrm{LAB}$ isolates tested against $L$. monocytogenes ATCC 7644. This result was further supported by in vivo study using $L$. monocytogenes infected rats. Administration of $L$. plantarum BSL for 9 days could be able to enhance total $L A B$ by 1.2 log unit in caecum and 1.4 log unit in faeces and caecum content of rats and showed inhibitory effects of $L$. monocytogenes by reducing the population upto $1.8 \mathrm{log}$ unit (caecum and caecum content) and 1.9 log unit (faeces) compared to control group. Histopathology analysis also demonstrated that administration of $L$. plantarum BSL could be able to reduce all types of liver and spleen damage observed but no change was found for $\lg A$ response compared to control.

\section{REFERENCES}

Aquilar, C., Vanegas, C. and Klotz, B. (2011) Antagonistic effect of Lactobacillus strains against Escherichia coli and Listeria monocytogenes in milk. Journal of Dairy Research 78, 136-143.

Amalaradjou, M. A. and Bhunia, A. K. (2012). Chapter 5: Modern approaches in probiotics research to control foodborne pathogens. Advance Food Nutrition Research 67, 185-239.

Arief, I. I., Jenie, B. S. L., Astawan, M. and Witarto, A. B. (2010). The effectivities of probiotic Lactobacillus plantarum 2C12 and Lactobacillus acidophilus 2B4 as antidiarrhea on rats. Available from http://www.medpet.journal.ipb.ac.id/ $\quad 33, \quad$ 137-143. [Retrieve on January 2017].

Association of Official Analytical Chemist (AOAC). (2005). Official Methods of Analysis. Washington, DC.

Bambirra, F. H. S., Lima, K. G. C., Franco, B. D. G. M., Cara, D. C., Nardi, R. M. D., Barbosa, F. H. F. and Nicoli, J. R. (2007). Protective effect of Lactobacillus sakei 2 a against experimental challenge with Listeria monocytogenes in gnotobiotic mice. Journal Society for Applied Microbiology 45, 663-667.

Carpentier, B. and Cerf, P. (2011). Persistence of Listeria monocytogenes in food industry equipment and premises. International Journal of Food Microbiology 145, 1-8.
Centers for Disease Control and Prevention (CDC). (2011). Available from http://www.cdc.gov/pregnancy/ infections-listeria.html. [Retrieve on September 2015]

Corr, S. C., Gahan, C. G. M. and Hill, C. (2007). Impact of selected Lactobacillus and Bifidobacterium species on Listeria monocytogenes infection and the mucosal immune response. Journal FEMS Immunology and Medical Microbiology 50, 380-388.

de Waard, D., Garssen, J., Bokken, G. C. A. M. and Vos, J. G. (2002). Antagonistic activity of Lactobacillus casei strain Shirota against gastrointestinal Listeria monocytogenes infection in rats. International Journal of Food Microbiology 73, 93-100.

dos Santos, L. M., Santos, M. M., Humberto, P. S. S., Rosa, M. E. A., Jacques, R. N. and Leda, Q. V. (2011). Monoassociation with probiotic Lactobacillus delbrueckii UFV-H2b20 stimulates the immune system and protects germfree mice against Listeria monocytogenes infection. Medical Microbiology and Immunology 200, 29-38.

Emmawati, A. (2015). Study of antiinfection properties of lactic acid bacteria isolated from mandai. Dr. Dissertation. Bogor Agricultural University, Indonesia.

Emmawati, A., Jenie, B. S. L., Nuraida, L. and Syah, D. (2015). Characterization of lactic acid bacteria isolates from mandai function as probiotic. Agritech 35, 146155.

Emmawati, A., Jenie, B. S. L., Nuraida, L. and Syah, D. (2016). Aggregation and adhesion abilities to enterocyte-like HCT-116 cells of probiotic candidates Lactobacillus plantarum strains isolated from "mandai", Indonesian fermented food against enteropathogens. International Food Research Journal 23, 2234-2240.

Food and Agricultural Organization (FAO)/World Health Organization (WHO). (2002a). Health and nutritional properties of probiotics in food including powder milk with live lactic acid bacteria e Joint Food and Agricultural Organization of the United Nations and World Health Organization Expert Consultation Report. Córdoba, Argentina.

Food and Agricultural Organization (FAO)/World Health Organization (WHO). (2002b). Guidelines for the evaluation of probiotics in food. Report of Joint FAO/WHO Working Group on drafting Guidelines for the evaluation of probiotics in food. London Ontario, Canada.

Food and Drug Administration (FDA). (2012). Foodborne pathogenic microorganisms and natural toxins. Handbook Listeria monocytogenes.

Gagnon, M. E. E., Kheadr, N., Dabour, D., Richard, I. and Fliss. (2006). Effect of Bifidobacterium thermacidofilum probiotic feeding on enterohemorrhagic Escherichia coli O157:H7 infection in BALB/c mice. International Journal of Food Microbiology 111, 26-33.

Galdeano, C. M. and Perdigón, G. (2006). The Probiotic Bacterium Lactobacillus casei Induces Activation of the Gut Mucosal Immune System through Innate Immunity. Clinical and Vaccine Immunology 13(2), 219-226. 
Gross, G., Wildner, G., Schonewille, A. and Rademaker, J. L. W. (2008). Probiotic Lactobacillus plantarum 299v does not counteract unfavorable phytohematoglutinin-induced changes in the rat intestinal microbiota. Journal Applied and Environmental Microbiology 74, 5224-5249.

Huang, R., Tao, X., Wan, C., Li, C., Xu, H., Xu, F., Nagendra, P., Shah and Wei, H. (2015). In vitro probiotic characteristics of Lactobacillus plantarum ZDY 2013 and its modulatory effect on gut microbiota of mice. International Dairy Journal 98, 1-12.

Jaradat, Z. W. and Bhunia, A. K. (2003). Adhesion, invasion, and translocation characteristics of Listeria Monocytogenes serotypes in Caco-2 cell and mouse models. Journal Applied and Environmental Microbiology 69, 3640-3645.

Jay, J. M., Loessner, M. and Golden, D. A. (2005). Modern Food Microbiology. $7^{\text {th }}$ edn. Springer. New York, USA.

Kamiya Biomedical Company (KBC). (2009). Available from http://www.kamiyabiomedical.com/03Clinical DiagnosticsProducts/Datasheets/KAI-004. [Retrieve on March 2016]

Kiernan, J. A. (1999). Histological and histochemichal methods: Theory \& Practice. Oxford: Pergamon press.

Kusumawati, N., Jenie, B. S. L., Setyahadi, S and Hariyadi, R. D. (2003). Selection indigenous lactic acid bacteria as probiotic strain with the ability to lower cholesterol. Journal of Microbiology Indonesia 8, 3943.

Kusumawati, N., Jenie B. S. L., Setyahadi, S and Hariyadi, R. D. (2008). Antibacterial activity of lactobacilli fermented food origin Indonesia against pathogens and their effects on the intestinal microflora rats. Journal of Medicine of Natural Materials 7, 69-75.

Lee, D. K., Park, J. E., Kim, M. J., Seo, J. G., Lee, J. H. and $\mathrm{Ha}, \mathrm{N}$. J. (2014). Probiotic bacteria, B. longum and $L$. acidophilus inhibit infection by rotavirus in vitro and decrease the duration of diarrhea in pediatric patients. Clinics and Research in Hepatology and Gastroenterology Journal 39, 237-244.

Leite, A. M. O., Miguel, M. A. L., Peixoto, R. S., Madiedo, P. R., Paschoalin, V. M. F., Mayo, B. and Delgado, S. (2015). Probiotic potential of selected lactic acid bacteria strains isolated from Brazilian kefir grains. International Dairy Journal 98, 3622-3632.

Liong, M. T. and Shah, N. P. (2006). Effects of a Lactobacillus casei synbiotic on serum lipoprotein, intestinal microflora and organic acids in rats. Journal of Dairy Science 89, 1390-1399.

Lomonaco, S., Decastelli, L., Nucera, D., Gallina, S., Bianchi, D. M. and Civera, T. (2009). Listeria monocytogenes in Gorgonzola: Subtypes, diversity and persistence over time. International Journal of Food Microbiology 128, 516-520.

Lourens-Hattingh, A. and Viljoen, B. C. (2001). Yogurt as probiotic carrier food. International Dairy Journal 11, 1-17.

Martins, F. S., Silva, A. A., Vieira, A. T., Barbosa, F. H. F., Arantes, R. M. E., Teixeira, M. M. and Nicoli, J.
R. (2009). Comparative study of Bifidobacterium animalis, Escherichia coli, Lactobacillus casei and Saccharomyces boulardii probiotic properties. Archives of Microbiology 191, 623-630.

Nuraida, L., Hana., Hartanti, W. A. and Prangdimurti, E. (2012). Potential of Lactobacillus isolated from breast milk to prevent diarrheae. Journal of Food Technology and Industry 23, 158-164.

Olivares, M., Diaz-Ropero, M. P., Marthin, R., Rodrigues, J. M and Xaus, J. (2006). Antimicrobial potential of four Lactobacillus strains isolated from breast milk. Journal of Applied Microbiology 101, 7279.

Oyetayo, V. O. (2004). Performance of rats orogastrically dosed with faecal strains of Lactobacillus acidophilus and challenged with Escherichia coli. African Journal of Biotechnology 3, 409-411.

Parvez, S., Malik, K. A., Kong, S. A. and Kim, H. Y. (2006). A review: Probiotics and their fermented food products are beneficial for health. Journal of Applied Microbiology 100, 1171-1185.

Ren, D., Li. C., Qin, Y., Ronglan Yin., Du, S., Liu, H., Zhang, Y., Wang, C., Rong, F. and Jin, J. (2015). Evaluation of immunomodulatory activity of two potential probiotic Lactobacillus strains by in vivo tests. Anaerobe 35, 22-27.

Saraou, T., Fall, P. A., Leroi, F., Antignac, J. P., Chéreau, S. and Pilet, M. F. (2016). Inhibition mechanism of Listeria monocytogenes by a bioprotective bacteria Lactococcus piscium CNCM I4031. Food Microbiology 53, 70-78.

Shah, N. P. (2007). Functional cultures and health benefits. Review. International Dairy Journal 17, 12621277.

Tulini, F. L., Winkelströter, L. K., Elaine, C. P. and de Martinis. (2013). Identification and evaluation of the probiotic potential of Lactobacillus paraplantarum FT259, a bacteriocinogenic strain isolated from Brazilian semi-hard artisanal cheese. Anaerobe 22, 57-63.

Ward, T. J. (2012). Chapter 3: Listeria monocytogenes. In: Molecular Typing in Bacterial Infections. Springer Sciences \& Business Media, New York, USA.

Williams, N. T. (2010). Probiotics. American Journal of Health-System Pharmacy 67, 449-458.

Wilson, A. R., Sigee, D and Epton, H. A. S. (2005). Antibacterial activity of Lactobacillus plantarum strain SK1 against Listeria monocytogenes is due to lactic acid producton. Journal of Applied Microbiology 99, 15161522. 